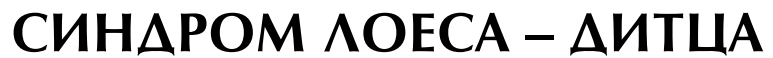 (обзор Аитературы и описание клинического случая)
}

\author{
(C) О.Е. Агранович, С.Ю. Семенов ${ }^{2}$, Е.Ф. Микиашвили ${ }^{1}$ С.В. Сараниева
}

${ }^{1}$ Федеральное государственное бюджетное учреждение «Национальный медицинский исследовательский центр детской травматологии и ортопедии имени Г.И. Турнера» Министерства здравоохранения Российской Федерации, Санкт-Петербург;

${ }^{2}$ Государственное бюджетное учреждение здравоохранения «Детская городская больница № 22», Санкт-Петербург;

${ }^{3}$ Федеральное государственное бюджетное учреждение «Петербургский институт ядерной физики им. Б.П. Константинова» Национального исследовательского центра «Курчатовский институт»

- Аля цитирования: Агранович О.Е., Семенов С.Ю., Микиашвили Е.Ф., Саранцева С.В. Синдром ^оеса-Аитца (обзор ^итературы и описание кминического случая) // Ортопедия, травматология и восстановительная хирургия детского возраста. - 2020. - Т. 8. - Вып. 1. C. 83-94. https://doi.org/10.17816/PTORS16047

Обоснование. Синдром Лоеса - Дитца - редкое аутосомно-доминантное заболевание соединительной ткани, характеризующееся патологией со стороны сердечно-сосудистой системы в сочетании с различными аномалиями опорно-двигательного аппарата. В современной литературе нет данных о частоте встречаемости патологии, а также не описан алгоритм обследования и лечения пациентов с данным синдромом.

Клиническое наблюдение. Представлено клиническое наблюдение пациента 7 лет с синдромом Лоеса - Дитца с генетически подтвержденным диагнозом.

Обсуждение. Приведен обзор литературы, рассмотрены вопросы диагностики и дифференциальной диагностики, а также клиническая картина синдрома. Основными симптомами синдрома Лоеса - Дитца являются аневризмы артерий (чаще всего корня аорты), извилистость артерий (преимущественно сосудов шеи), гипертелоризм и расщепленный или широкий язычок. Однако данные признаки не всегда присутствуют у всех пациентов с этим заболеванием.

Заключение. Генетическая верификация заболевания, а также мультидисциплинарный подход к лечению с обязательным динамическим наблюдением таких специалистов, как кардиолог, невролог, ортопед, педиатр, позволяют предупреждать развитие осложнений и увеличивать продолжительность жизни пациентов с синдромом Лоеса - Дитца.

Ключевые слова: синдром Лоеса - Дитца; аневризма и расслоение аорты; генерализованная извитость артерий; трансформирующий фактор роста $\beta$.

\section{LOEYS-DIETZ SYNDROME (literature review and case description)}

(C) O.E. Agranovich ${ }^{1}$, S.Yu. Semenov ${ }^{2}$, E.F. Mikiashvili ${ }^{1}$, S.V. Sarantseva ${ }^{3}$

${ }^{1}$ H. Turner National Medical Research Center for Children's Orthopedics and Trauma Surgery, Saint Petersburg, Russia;

${ }^{2}$ Children's City Hospital No. 22, Saint Petersburg, Russia;

${ }^{3}$ Petersburg Nuclear Physics Institute named by B.P. Konstantinov of National Research Centre "Kurchatov Institute", Saint Petersburg, Russia

- For citation: Agranovich OE, Semenov SYu, Mikiashvili EF, Sarantseva SV. Loeys-Dietz syndrome (literature review and case description). Pediatric Traumatology, Orthopaedics and Reconstructive Surgery. 2020;8(1):83-94. https://doi.org/10.17816/PTORS16047 
Background. The Loeys-Dietz syndrome is a rare autosomal dominant connective tissue disorder characterized by the pathology of the cardiovascular system in combination with various anomalies of the musculoskeletal system. In modern literature, there is neither any information about the frequency of pathology nor any algorithm of examination and treatment for patients with this syndrome.

Clinical case. The article presents a clinical observation of a 7-year-old patient with Loeys-Dietz syndrome with a genetically confirmed diagnosis.

Discussion. This article provided a literature review, examined diagnosis issues and differential diagnosis, and presented the clinical picture of the syndrome. The main symptoms of Loeys-Dietz syndrome are artery aneurysms (most often in the aortic root), arterial tortuosity (mainly the vessels of the neck), hypertelorism, and bifid (split) or broad uvula. However, the combination of these symptoms is not found in all patients with this disease.

Conclusions. The article emphasized the importance of a genetic verification of the disease, as well as a multidisciplinary approach to treatment with mandatory dynamic monitoring by specialists such as a cardiologist, neurologist, orthopedist, and pediatrician, which help prevent the development of complications and increase the life expectancy of this group of patients.

Keywords: Loeys-Dietz syndrome; aneurysm and dissection of the aorta; generalized tortuosity of the artery; transforming growth factor- $\beta$.

Синдром Лоеса - Дитца (Loeys-Dietz) - редкое аутосомно-доминантное заболевание соединительной ткани, характеризующееся патологией со стороны сердечно-сосудистой системы (аневризматическое расширение и расслоение аорты и других артерий среднего и крупного калибра, генерализованная извитость артерий с агрессивным характером прогрессирования) в сочетании с различными аномалиями опорно-двигательной системы [1].

Впервые данное заболевание было описано бельгийским врачом Bart L. Loeys и американским врачом Harry S. Dietz в 2005 г. [2, 3]. По мнению авторов, конкретных клинических критериев данного синдрома не существует, а клинический диагноз должен быть подтвержден молекулярно-генетическим тестом с обнаружением специфических мутаций [1].

Вероятность рождения ребенка с данной патологией, если один из родителей страдает синдромом Лоеса - Дитца, составляет 50 \%. Около $25 \%$ пациентов имеют близких родственников

Таблица 1

Типы синдрома Аоеса - Аитца

\begin{tabular}{|l|c|c|}
\hline \multicolumn{1}{|c|}{ Тип } & Хромосома & Ген \\
\hline $\begin{array}{l}\text { Синдром Лоеса - Дитца } \\
\text { 1-го типа }\end{array}$ & 9q22.33 & TGFBR1 \\
\hline $\begin{array}{l}\text { Синдром Лоеса - Дитца } \\
\text { 2-го типа }\end{array}$ & $3 \mathrm{q} 24.1$ & TGFBR2 \\
\hline $\begin{array}{l}\text { Синдром Лоеса - Дитца } \\
\text { 3-го типа }\end{array}$ & $15 \mathrm{q} 22.33$ & $S M A D 3$ \\
\hline $\begin{array}{l}\text { Синдром Лоеса - Дитца } \\
\text { 4-го типа }\end{array}$ & $1 \mathrm{q} 41$ & TGFB2 \\
\hline $\begin{array}{l}\text { Синдром Лоеса - Дитца } \\
\text { 5-го типа }\end{array}$ & $14 \mathrm{q} 24.3$ & TGFB3 \\
\hline $\begin{array}{l}\text { Синдром Лоеса - Дитца } \\
\text { 6-го типа }\end{array}$ & Нет & $S M A D 2$ \\
\hline
\end{tabular}

с таким же диагнозом, в 75 \% случаев заболевание возникает de novo [4].

Примерно три четверти пациентов с синдромом Лоеса - Дитца обладают характерными краниальными и лицевыми признаками заболевания (расщелина нёба, гипертелоризм и/или краниосиностоз) [4]. Клинически синдром обычно проявляется в течение первого года жизни, в том числе и сразу после рождения, но первые признаки могут появиться и в зрелом возрасте [5-7]. Известны сообщения о выявлении симптомов этого синдрома у плода [8-10].

Заболевание характеризуется неблагоприятным прогнозом. Данные о средней продолжительности жизни пациентов с синдромом Лоеса - Дитца различные - от 26 до 37 лет $[2,11]$. Летальный исход обычно наступает из-за расслоения или разрыва аневризмы аорты, других артерий крупного калибра и внутричерепных кровоизлияний [12].

Генетическими причинами синдрома Лоеса - Дитца являются мутации в генах, кодирующих рецепторы трансформирующего фактора роста $\beta_{1}$ и $\beta_{2}$ (TGFBR1 и TGFBR2) [1]. Впоследствии было определено, что мутации в гене SMAD3, в генах-лигандах трансформирующего фактора роста $\beta_{2}$ и трансформирующего фактора роста $\beta_{3}$ (TGFB2 и TGFB3) также связаны с фенотипическими особенностями, обусловленными синдромом Лоеса - Дитца [1, 13-17]. Таким образом, мутации во всех этих пяти генах демонстрируют измененную передачу сигналов трансформирующего фактора роста $\beta$ (TGF- $\beta$ ), что клинически проявляется сходными изменениями со стороны сердечно-сосудистой системы, а также черепнолицевыми и скелетными аномалиями [2, 3, 13-16]. Josephina A. N. Meester et al. (2017) сообщили о наличии шестого типа синдрома Лоеса - Дитца с дефектом в гене SMAD2 без уточнения клинических особенностей [18] (табл. 1). 
Мы не обнаружили в литературе описания клинических признаков, характерных для конкретного типа синдрома. Для подтверждения диагноза и его верификации необходимо проведение молекулярно-генетического исследования с целью выявления специфических мутаций.

Достоверно оценить частоту встречаемости синдрома Лоеса - Дитца в популяции в настоящее время не представляется возможным ввиду отсутствия масштабных эпидемиологических исследований.

\section{КАиническое наблюдение}

Под нашим наблюдением находится мальчик 7 лет с пороками развития верхних и нижних конечностей, патологией сердечно-сосудистой и нервной систем. Из анамнеза известно, что ребенок от пятой беременности, протекавшей на фоне токсикоза. Роды третьи срочные оперативные. Наследственный анамнез по основному заболеванию не отягощен. В I триместре беременности мать перенесла ОРВИ, а также получала антибактериальную терапию против хламидийной инфекции. При скрининговом ультразвуковом обследовании на 32-33-й неделе беременности у плода выявлены признаки врожденной косолапости. Вес ребенка при рождении - 3500 г, длина тела -54 см. При первом клиническом осмотре обнаружены врожденная косолапость, деформация кистей, признаки черепно-лицевого диморфизма, гидроцефалия. С возраста 2 мес. в одном из лечебных учреждений России проводилось лечение косолапости по методике Понсети. В 2 года мальчику была выполнена операция - задний релиз голеностопного и подтаранного суставов, транспозиция сухожилий передней большеберцовой мышцы на III клиновидную кость на левой стопе, тенотомия сухожилий длинных сгибателей I-V пальцев левой стопы и II-III пальцев правой стопы.

При клиническом ортопедическом осмотре ребенка при поступлении установлено следующее (см. рисунок). Телосложение гипостеническое. Ходит самостоятельно, прихрамывая на левую ногу, слегка сгибает ноги в коленных суставах, перекат стоп нарушен, варусное положение стоп. Череп деформирован - скафоцефалия в сочетании с правосторонней затылочной плагиоцефалией, выраженные лобные бугры. Высокое нёбо. Микрогнатия, ретрогения. Короткая спинка носа и гипоплазия крыльев носа. Гипертелоризм. Голубые склеры. Низкое расположение ушных раковин. Повышенная эластичность кожи. Грудная клетка узкая, килевидная деформация, отмечается парастернальное симметричное вдавление ребер. Асимметрия надплечий, углов лопаток. Ось позвоночника отклонена вправо в грудопоясничном отделе. Асимметрия паравертебральных мышц. Правосторонний грудопоясничный сколиоз I степени (угол сколиотической дуги $-9^{\circ}$ ). Отмечаются признаки дисплазии соединительной ткани: избыточное разгибание в локтевых и пястнофаланговых, коленных суставах. Разгибательные контрактуры в лучезапястных суставах пассивно корригируются. Первые лучи кистей находятся в положении оппозиции. На правой кисти: сгибательные контрактуры в проксимальных межфаланговых суставах III и IV пальцев правой кисти под углом $145^{\circ}$, не корригируются; V палец - сгибательная контрактура в проксимальном межфаланговом суставе под углом $90^{\circ}$, не корригируется. На левой кисти - сгибательные контрактуры в проксимальных межфаланговых суставах II, III IV, V пальцев под углом $160^{\circ}$, частично корригируются. Ульнарная девиация $\mathrm{V}$ пальцев обеих кистей. Функция двустороннего схвата обеих кистей сохранена. В коленных суставах сгибание $-30^{\circ}$, переразгибание $-25^{\circ}$. Вальгусная деформация в коленных суставах: справа $-20^{\circ}$, слева $-10^{\circ}$. Внутренняя торсия костей голени: справа $-20^{\circ}$, слева $-10^{\circ}$. Правая стопа: кавусная деформация с приведением переднего отдела, варус пяточной кости. Левая стопа: пяточная деформация, уплощение продольного свода.

При рентгенологическом исследовании кистей и стоп выявлено следующее. Умеренное уменьшение размеров костей левой кисти, приведение I пальцев кистей $(S>D)$, выраженная ульнарная девиация в пястно-фаланговых суставах V пальцев обеих кистей, сгибательные контрактуры и ульнарная девиация в проксимальных межфаланговых суставах III и IV пальцев обеих кистей. Многоплоскостная деформация обоих стоп. Правая стопа - передний отдел приведен, признаки супинации, ладьевидная кость в положении выраженной наружной тыльной децентрации, деформация продольного свода с локацией вершины каудально, признаки экскавации продольного свода, умеренный остеопороз. Левая стопа - приведена, продольный свод значительно уплощен, выраженная тыльно-варусная децентрация ладьевидной кости (на границе с подвывихом), умеренное укорочение I плюсневой кости, умеренный остеопороз.

При рентгенографии позвоночника отмечено резкое выпрямление физиологических изгибов в сагиттальной плоскости, умеренное лордозирование на уровне $\mathrm{Th}_{6}-\mathrm{Th}_{9}$. Перекос таза вправо. Spina bifida posterior displastica позвонков $\mathrm{S}_{1}-\mathrm{S}_{2}$ без 

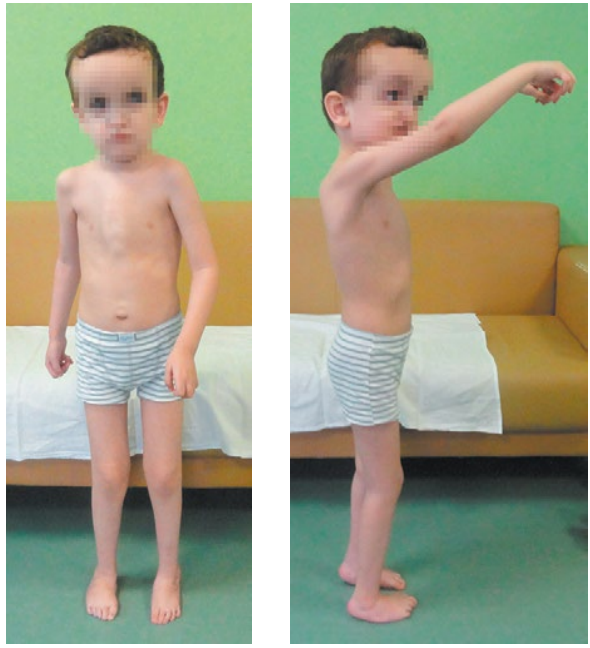

$a$

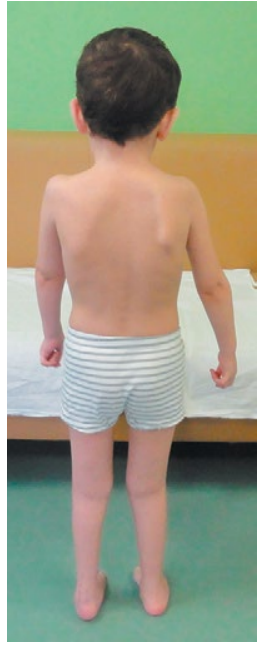

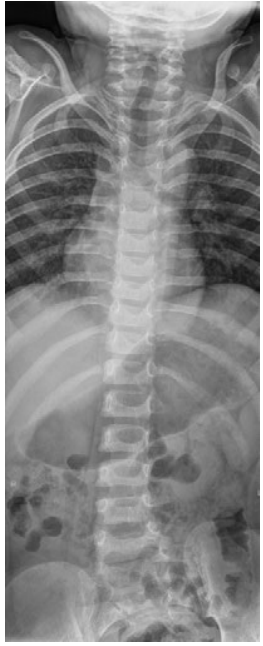

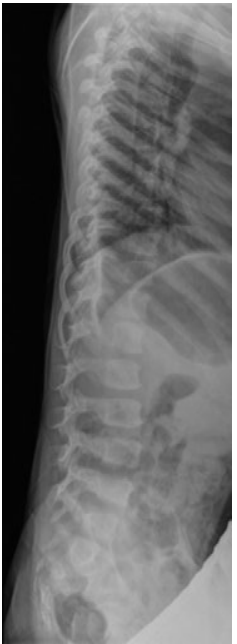

6

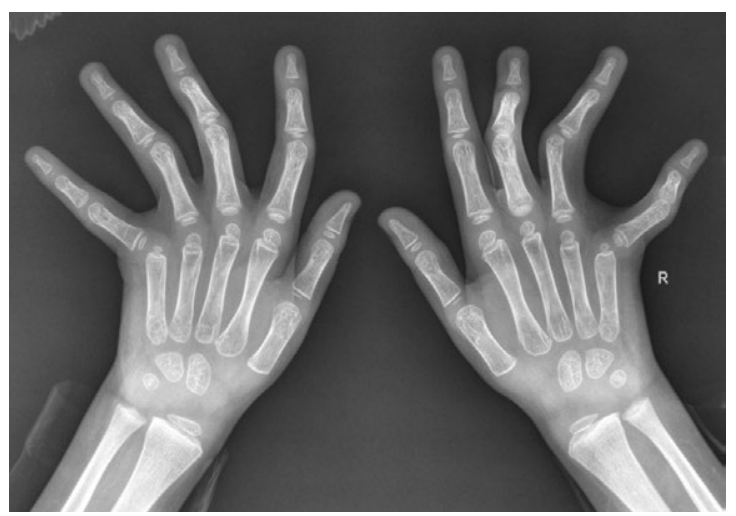

B
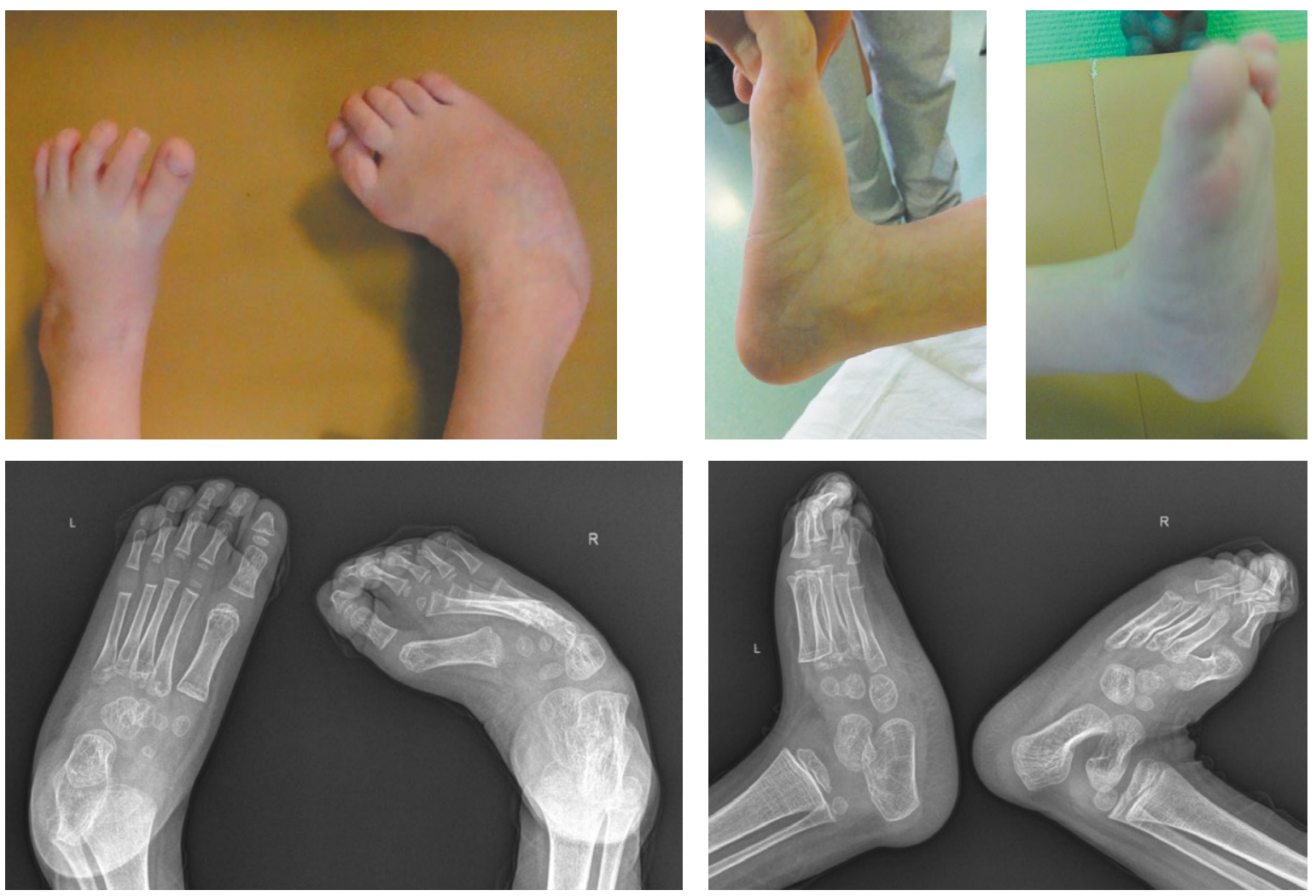

Пациент А.: $a-$ внешний вид пациента; $\sigma$ - рентгенограммы позвоночника; 6 - внешний вид и рентгенограммы кистей; 2 - внешний вид и рентгенограммы стоп 
изменения размеров позвоночного канала. Признаки нестабильности на уровне $\mathrm{L}_{5}-\mathrm{S}_{1}$ (смещение тела позвонка $\mathrm{L}_{5}$ кпереди до 4 мм). Вертикальное положение крестца.

При эхокардиографии с цветным доплеровским исследованием было обнаружено небольшое расширение корня аорты (до 15 мм). Пациент был консультирован кардиологом. Заключение: «Патологии сердца не выявлено, небольшое расширение корня аорты, НК-0».

Мальчик был осмотрен неврологом. Заключение: «Резидуальная энцефалопатия, реконвалесцент внутрижелудочкового кровотечения, перивентрикулярная лейкомаляция, смешанная сообщающаяся гидроцефалия, псевдобульбарная дизартрия, миопатический симптомокомплекс в структуре генетического синдрома».

При осмотре офтальмолога были выявлены гипертелоризм, гиперметропия слабой степени, изменения со стороны глазного дна отсутствовали.

С целью верификации заболевания было выполнено молекулярно-генетическое обследование методом таргентного секвестрирования ДНК с использованием панели «Синдром Марфана и марфаноподобные синдромы». Исследование проведено по методике селективного захвата участков ДНК, относящихся к кодирующим областям генов с известным клиническим значением, в том числе ACTA2, COL3A1, COL5A1, COL5A2, FBN1, FBN2, MYH11, SLC2A10, SMAD3, TGFB2, TGFBR1, TGFBR2. Выявлена ранее не описанная гетерозиготная мутация в экзоне 6 гена TGFBR2 (chr3:30715721G>C), приводящая к замене аминокислоты в позиции 485 белка (p.Arg485Pro, NM_001024847.2). Гетерозиготные мутации в гене TGFBR2 описаны у пациентов с синдромом Лоеca - Дитца 2-го типа (OMIM:610168). В дальнейшем ребенок был консультирован генетиком и на основании результатов обследования был диагностирован синдром Лоеса - Дитца 2-го типа с аутосомно-доминантным типом наследования.

\section{ОбсужАение}

Основными симптомами синдрома Лоеса Дитца являются:

- аневризмы артерий (чаще всего корня аорты);

- извилистость артерий (преимущественно сосудов шеи);

- гипертелоризм;

- расщепленный или широкий язычок.

Однако следует помнить, что данные признаки сочетаются не у всех пациентов с этим заболеванием [19].

\section{Патология сердечно-сосудистой системы при синдроме Лоеса - Дитца}

У пациентов с синдромом Лоеса - Дитца 1-го или 2-го типа с тяжелым черепно-лицевым диморфизмом особенно высок риск разрыва аневризм в раннем возрасте и при меньших размерах, чем у пациентов с изолированными аневризмами сосудов или с другими синдромами, в клинической картине которых присутствует патологическое расширение артерий $[2,3]$. В литературе есть сообщения о диагностированных расслоениях аорты у лиц в возрасте 3 мес. и о церебральном кровоизлиянии в возрасте до 3 лет [20, 21].

у больных с синдромом Лоеса - Дитца 1-го и 2-го типов более часто встречаются врожденные пороки сердца, такие как двустворчатый аортальный клапан, дефект межпредсердной перегородки или открытый артериальный проток, чем в общей популяции $[4,22]$. Пролапс и/или недостаточность митрального клапана от легкой до тяжелой степени можно наблюдать при всех типах синдрома $[13,22,23]$. Мерцательную аритмию и гипертрофию левого желудочка наиболее часто регистрируют у лиц с синдромом Лоеса - Дитца 3-го типа (в $24 \%$ случаев), однако они могут наблюдаться упациентов и с другими типами данного синдрома [1]. Некоторые авторы сообщают, что гипертрофия левого желудочка у людей с этим синдромом обычно бывает легкой или умеренной степени тяжести и возникает при отсутствии аортального стеноза или артериальной гипертензии [21, 24]. B.M. Loeys et al. (2006) и P.M. Eckman et al. (2009) описали нарушение систолической функции левого желудочка у больных синдромом Лоеса - Дитца $[3,25]$.

По мнению М. Arslan-Kirchner et al. (2011), всем пациентам с синдромом Лоеса - Дитца необходимо проводить эхокардиографическое исследование как минимум 1 раз в год для наблюдения за состоянием корня аорты, восходящей аорты и клапанов сердца [26].

Решение о проведении операции на аорте обычно основывается на анализе комплекса данных: динамическом определении анатомических показателей аорты, функции клапанов, выраженности некардиальных особенностей, семейном анамнезе и информации о генотипе $[3,27]$.

Ввиду активного характера прогрессирования аневризмы аорты и высокого риска ее разрыва показанием к хирургическому вмешательству на аорте служит размер ее корня, равный 4,0 см у взрослых [1]. У детей операцию откладывают до тех пор, пока диаметр корня аорты не увеличится до 2,0-2,2 см. Однако если расширение аорты происходит медленно, то в некоторых случаях у детей операцию выполняют, 
когда размер корня аорты приближается к порогу 4,0 см [1]. Быстрое увеличение размера диаметра корня аорты (>0,5 см в год) должно также стать показанием к ранней хирургической коррекции.

Открытое восстановление нисходящих и торакоабдоминальных аневризм является предпочтительным, потому что эндоваскулярное восстановление может привести к поздним осложнениям из-за продолжающейся дилатации зоны или постоянной перфузии ложного просвета $[20,26]$. Стентирование может быть оправдано при нисходящем разрыве грудного отдела аорты или для облегчения синдромов гиперперфузии, таких как рецидивирующая гипертензия или неправильная перфузия почечной артерии, вторичная по отношению к острой диссекции. Описаны случаи полной поэтапной замены аорты у пациентов с синдромом Лоеса - Дитца [28]. Послеоперационную эхокардиографию с интервалом от 3 до 6 мес. рекомендуют выполнять в течение года после операции и затем раз в 6 мес. [29].

Помимо динамического наблюдения и хирургической коррекции аорты и пораженных артерий необходимо использовать лекарственные препараты, снижающие артериальное давление, избегать приема лекарств, которые действуют как стимуляторы или вазоконстрикторы, а также ограничить физические нагрузки. Пациентам с данной патологией запрещены занятия спортом [1]. В случае диагностики синдрома Лоеса - Дитца у детей до года показано назначение ранней терапии ингибиторами ангиотензин-превращающего фермента или бета-блокаторами для контроля скорости прогрессирования дилатации аорты [1].

Патологическая извитость артерий может быть генерализованной, но чаще всего наблюдается в сосудах шеи и головы при всех типах синдрома Лоеса - Дитца $[3,4,13]$. Для диагностики состояния артерий считают целесообразным проведение магнитно-резонансной или компьютерной ангиографии с построением трехмерных изображений сосудов головы, шеи, груди, живота и таза. Поскольку при магнитно-резонансной томографии отсутствует лучевая нагрузка, именно этому методу отдают предпочтение. Полную визуализацию сосудов у детей необходимо осуществлять при первоначальной диагностике и затем с интервалом около 2 лет, если не обнаружены аневризмы и диссекции $[2,3]$.

\section{Ортопедическая патология при синдроме Лоеса - Дитца}

Аномалии скелета при синдроме Лоеса - Дитца включают деформацию грудной клетки (чаще воронкообразная и реже - килевидная), по- звоночника (сколиоз), конечностей (врожденная косолапость, арахнодактилия, камптодактилия, вывихи в пястно-фаланговых суставах, вывихи костей предплечья, разгибательные контрактуры суставов), а также аномалии черепа. Зарегистрированы случаи гипермобильности суставов, множественные подвывихи суставов, врожденные вывихи бедра у пациентов с синдромом Лоеca - Дитца [3]. На первом году жизни у таких детей обычно наблюдается сниженный мышечный тонус. При этом важно помнить, что при выполнении упражнений для стимуляции тонуса мышц необходимо исключать приемы с гиперэкстензией [5].

Из деформаций стоп встречается косолапость или плоскостопие. Врожденная косолапость у таких пациентов хорошо поддается консервативной терапии, если деформация не сильно выражена. Хирургическое вмешательство, как правило, не рекомендуется, поскольку оно, как правило, приводит к чрезмерной коррекции (вальгус заднего отдела стопы) [30]. Оперативное вмешательство при плоскостопии также не показано за исключением случаев возникновения сильного болевого синдрома, ограничивающего ходьбу [1].

Патология шейного отдела позвоночника является характерным признаком синдрома Лоеса - Дитца 1-го и 2-го типов и встречается в $51 \%$ случаев $[3,31]$. Наиболее часто выявляют дефекты дуг шейных позвонков, подвывихи позвонков $\mathrm{C}_{1}$ и $\mathrm{C}_{2}$, приводящие к нестабильности шейного отдела позвоночника [32].

Из патологии позвоночника наиболее часто развиваются прогрессирующие сколиотические и кифотические деформации, а также спондилолистез. В этом случае необходимо динамическое наблюдение не реже одного раза в год до наступления зрелости скелета [3, 29].

Остеоартрит и остеоартроз являются характерной особенностью пациентов с синдромом Лоеса - Дитца 3-го типа. Обычно артроз поражает коленные, тазобедренные суставы, мелкие суставы рук и ног, суставы позвоночника уже в подростковом возрасте, в связи с чем проводят консервативное лечение [13, 21].

В литературе представлены сообщения о низкой минеральной плотности костной ткани и о частых переломах у молодых людей с синдромом Лоеса - Дитца [2, 30, 31].

\section{Другие клинические проявления синдрома Лоеса - Дитца}

У пациентов с синдромом Лоеса - Дитца часто отмечают признаки черепно-лицевого диморфизма. Считают, что гипертелоризм и аномалии неб- 
ного язычка (двудольный, широкий или длинный язычок) являются характерными признаками, однако у многих пациентов с данным синдромом эти симптомы отсутствуют [1].

Расщелина нёба и краниосиностоз наблюдаются у пациентов с первыми двумя типами синдрома. Чаще всего отмечается преждевременное закрытие сагиттального шва с формированием долихоцефалии, но могут быть задействованы и другие швы черепа [1].

Другие черепно-лицевые особенности синдрома Лоеса - Дитца представлены микро- или ретрогнатией, уплощением скул, высоким и широким лбом с высокой передней линией роста волос [18].

Больные синдромом Лоеса - Дитца подвержены высокому риску развития аллергических реакций, включая бронхиальную астму, пищевую аллергию, аллергический ринит, атопический дерматит и экзему [33]. По данным G. MacCarrick et al. (2014), у пациентов с данным синдромом в $31 \%$ случаев наблюдается пищевая аллергия (по сравнению с 6-8 \% распространенности среди населения в целом). Степень тяжести аллергических реакций различна. Антигистаминные препараты рекомендованы для лечения кожных или более легких аллергических реакций; применение адрено- и симпатомиметиков у лиц с данным синдромом ограничено из-за их прессорного эффекта на сосуды, в связи с этим их использование оправдано лишь в случаях тяжелых аллергических реакций [1].

У пациентов с синдромом Лоеса - Дитца 2-го типа кожа бархатная, тонкая, полупрозрачная [3], поэтому заживление ран обычно происходит длительно, а рубцы обычно формируются атрофические [25].

G. MacCarrick et al. (2014) отмечают более частую встречаемость паховых, пупочных грыж у детей с синдромом Лоеса - Дитца, чем в популяции в целом [1].

В литературе представлены сообщения о спонтанном разрыве кишечника и селезенки у пациентов с этим синдромом [18].

Умственная отсталость, неспособность к обучению - редкое явление у людей с данным синдромом и, вероятно, связано с краниосиностозом или гидроцефалией. Нет данных о нарушении ментальных функций у лиц при синдроме Лоеса - Дитца 3-го типа [1].

Мальформация Арнольда - Киари при этом синдроме наблюдается редко. Может развиваться гидроцефалия, но она обычно не связана с пороком Киари. Дуральную эктазию в настоящее время все чаще обнаруживают у пациентов с син- дромом Лоеса - Дитца, что обусловлено широким применением современных методов лучевой диагностики [29].

Офтальмологические проблемы при синдроме Лоеса - Дитца включают косоглазие (чаще экзотропия), амблиопию, катаракту. У лиц с этим синдромом нередко наблюдаются голубые склеры. Близорукость встречается редко [3].

Синдром Лоеса - Дитца ассоциирован с высокой распространенностью эозинофильной болезни желудочно-кишечного тракта (EGID - eosinophilassociated gastrointestinal disoders) [32]. По данным G. MacCarrick et al. (2014), у пациентов с данной патологией развиваются эозинофильный эзофагит, эозинофильный гастрит и/или эозинофильный колит [1].

Дети с синдромом Лоеса - Дитца часто плохо прибавляют в весе [32].

Основные симптомы синдрома Лоеса - Дитца представлены в табл. 2 [19].

При лечении пациентов с этим синдромом необходимо помнить о возникновении таких грозных осложнений, как:

1) смерть в результате разрыва аневризмы аорты;

2) инсульт вследствие разрыва аневризмы артерий шеи;

3) спонтанный пневмоторакс;

4) гемоптизис;

5) отслойка сетчатки;

6) разрыв полых органов (кишечника, матки), селезенки [19].

Дифференциальную диагностику синдрома Лоеса - Дитца следует проводить с такими заболеваниями, как синдромы Марфана, Билса, Элерса - Данло.

Синдром Марфана (Marfan syndrome) имеет аутосомно-доминантный тип наследования и вызван мутациями гена фибриллина-1 (FBN1). Ключевыми первичными проявлениями синдрома Марфана являются дилатация корня аорты и эктопия хрусталика. По сравнению с синдромом Марфана у пациентов с синдромом Лоеса - Дитца наблюдается злокачественное и прогрессирующее течение аневризмы аорты и извилистости сосудов артериального русла; аневризмы аорты имеют тенденцию расслаиваться и разрываться при меньшем диаметре и в более молодом возрасте; аневризмы при синдроме Лоеса - Дитца не ограничиваются корнем или восходящей частью аорты, часто затрагивают другие крупные сосуды и сосуды головного мозга [18]. Врожденные пороки сердца при синдроме Марфана встречаются гораздо реже по сравнению с синдромом Лоеса - Дитца [34]. Гипермобильность суставов наблюдается у большинства пациентов с синдромом Марфана, в то 


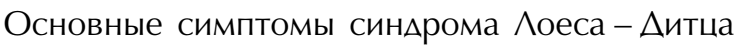

\begin{tabular}{|c|c|}
\hline Локализация & Симптомы \\
\hline Сердечно-сосудистая система & $\begin{array}{l}\text { Врожденные пороки сердца: открытый артериальный проток, дефект } \\
\text { межпредсердной или межжелудочковой перегородки и двустворчатый } \\
\text { аортальный клапан }\end{array}$ \\
\hline Орган зрения & $\begin{array}{l}\text { Миопия (близорукость) } \\
\text { Патология глазных мышц } \\
\text { Отслоение сетчатки }\end{array}$ \\
\hline Черепно-лицевая область & $\begin{array}{l}\text { Плоские скулы } \\
\text { Небольшой наклон вниз к глазам } \\
\text { Краниосиностоз } \\
\text { Расщелина нёба } \\
\text { Голубые склеры } \\
\text { Микрогнатия и/или ретрогнатия }\end{array}$ \\
\hline Опорно-двигательный аппарат & $\begin{array}{l}\text { Длинные пальцы кистей и стоп } \\
\text { Контрактуры пальцев } \\
\text { Косолапость } \\
\text { Сколиоз } \\
\text { Нестабильность шейного отдела позвоночника } \\
\text { Гипермобильность суставов } \\
\text { Воронкообразная деформация грудной клетки/килевидная деформа- } \\
\text { ция грудной клетки } \\
\text { Остеоартрит } \\
\text { Нормальный рост }\end{array}$ \\
\hline Кожа & $\begin{array}{l}\text { Полупрозрачная } \\
\text { Мягкая или бархатистая } \\
\text { Легко травмируется } \\
\text { Атрофические рубцы } \\
\text { Грыжи передней брюшной стенки }\end{array}$ \\
\hline Прочее & $\begin{array}{l}\text { Пищевая или экологическая аллергия } \\
\text { Воспалительные заболевания желудочно-кишечного тракта } \\
\text { Полые органы (кишечник, матка) и селезенка склонны к разрыву }\end{array}$ \\
\hline
\end{tabular}

время как при синдроме Лоеса - Дитца наличие этого признака зависит от дефекта определенного гена. Пациентов с синдромом Лоеса - Дитца 3-го типа чаще всего отличает гипермобильность суставов с дегенеративными изменениями в них [21]. Арахнодактилия более выражена у пациентов с синдромом Марфана. Контрактуры суставов у пациентов с синдромом Лоеса - Дитца определяются чаще. Общими скелетными особенностями синдрома Лоеса - Дитца и синдрома Марфана являются сколиотические деформации позвоночника, плоскостопие, деформации грудной клетки, дуральная эктазия. Отсутствуют данные об эктопии хрусталика у пациентов с синдромом Лоеса - Дитца, в то время как при синдроме Марфана это основная отличительная черта [18]. Близорукость при синдроме Марфана встречается намного чаще, чем при синдроме Лоеса - Дитца [1]. Голубые склеры описаны у пациентов с синдромом Лоеса - Дитца и обычно не наблюдаются у лиц с синдромом Марфана [3]. У некоторых людей с синдромом Лоеса - Дитца без черепно-лицевых особенностей кожные признаки (тонкая, бархатная, полупрозрачная кожа) могут быть заметной отличительной чертой в сравнении с синдромом Марфана $[4,13]$. Гипертелоризма и аномалий небного язычка у пациентов с синдромом Марфана не описано [18].

Синдром Элерса - Данло (Ehlers-Danlos syndrome - EDS) представляет собой группу заболеваний соединительной ткани, клинически и генетически неоднородных. При этом все подтипы характеризуются аномалиями кожи, связок и суставов, кровеносных сосудов, внутренних органов, скелетными патологиями (воронкообразная деформация грудной клетки, плоскостопие, кифосколиоз) [18]. Гипермобильность суставов, гиперчувствительность кожи и «хрупкость» мягких тканей - наиболее типичные проявления. До четверти пациентов с синдромом Элерса - Данло страдают аневризмой аорты [35]. Синдром Элерса - Данло вызывается мутациями в генах, кодирующих фибриллы коллагена или белки, участвующие в процессинге этих коллагенов [18]. При заживлении у пациентов с синдромом Элерса Данло формируются «папиросные» или келоид- 
ные рубцы [36] в отличие от атрофических рубцов при синдроме Лоеса - Дитца.

Синдром Билса (Beals syndrome) - редкое аутосомно-доминантное заболевание соединительной ткани, характеризующееся арахнодактилией, врожденными контрактурами суставов, сколиотической деформацией позвоночника, деформацией грудной клетки, плоскостопием и измененной формой ушных раковин («мятое ухо»). Заболевание обусловлено мутацией гена фибриллина-2 (FBN2) [36]. Синдром Билса в отличие от синдрома Лоеса - Дитца считают доброкачественным заболеванием, при котором особенности сердечно-сосудистой системы в большинстве случаев ограничены пролапсом митрального клапана. Однако примерно у 15-20 \% пациентов с синдром Билса регистрируют аневризму аорты; встречаются и другие врожденные пороки сердца. В отличие от синдрома Лоеса - Дитца при синдроме Билса врожденные контрактуры суставов с возрастом имеют тенденцию к обратному развитию [36].

I. Valenzuela et al. рекомендуют проводить дифференциальную диагностику синдрома Лоеca - Дитца с врожденным множественным артрогрипозом. Однако при артрогрипозе отсутствуют изменения со стороны сердечно-сосудистой системы, характерные для данного синдрома [37].

При подозрении на синдром Лоеса - Дитца пациенту необходимо выполнять весь комплекс дополнительных обследований, включающий:

1) ультразвуковое исследование сердца с последующей консультацией кардиолога;

2) КТ-ангиографию или магнитно-резонансную томографию для оценки артериального русла головы, шеи, грудной клетки, брюшной полости и таза;

3) консультацию невролога;

4) консультацию окулиста;

5) консультацию генетика;

6) проведение молекулярно-генетического обследования пациента и его родителей для выявления мутаций в генах TGFBR1, TGFBR2, SMAD3, TGFB2 и TGFB3.

\section{ЗакАючение}

Таким образом, синдром Лоеса - Дитца представляет собой заболевание, при котором необходимо динамическое наблюдение за ребенком со стороны многих специалистов, прежде всего кардиолога, невролога, ортопеда, педиатра. Ранняя диагностика данного синдрома, грамотное ведение пациента позволят предупредить развитие осложнений и увеличить продолжительность жизни пациентов с этим синдромом.
Следует продолжить изучение сравнительно недавно открытого генетического синдрома с полиморфизмом клинических проявлений и публикации новых клинических наблюдений.

\section{Аополнительная информация}

Источник финансирования. Авторы заявляют об отсутствии финансирования при проведении исследования.

Конфликт интересов. Авторы декларируют отсутствие явных и потенциальных конфликтов интересов, связанных с публикацией настоящей статьи.

Этическая экспертиза. Авторы получили письменное согласие законных представителей пациента на анализ и публикацию медицинских данных.

\section{Вклад авторов}

О.Е. Агранович - хирургическое лечение пациента, обзор литературы, сбор и анализ литературных источников, написание текста и редактирование статьи.

С.Ю. Семенов - обзор литературы, сбор и анализ литературных источников, подготовка и написание текста статьи.

Е.Ф. Микиашвили - курация, хирургическое лечение пациента, сбор и анализ литературных источников, подготовка и написание текста статьи.

С.В. Сараниева - обзор литературы, сбор и анализ литературных источников, написание текста и редактирование статьи.

Все авторы внесли существенный вклад в проведение исследования и подготовку статьи, прочли и одобрили финальную версию перед публикацией.

\section{Аитература}

1. MacCarrick G, Black $\mathrm{JH}, 3^{\text {rd }}$, Bowdin S, et al. Loeys-Dietz syndrome: a primer for diagnosis and management. Genet Med. 2014;16(8):576-587. https:// doi.org/10.1038/gim.2014.11.

2. Loeys BL, Schwarze U, Holm T, et al. Aneurysm syndromes caused by mutations in the TGF-beta receptor. N Engl J Med. 2006;355(8):788-798. https://doi. org/10.1056/NEJMoa055695.

3. Loeys BL, Chen J, Neptune ER, et al. A syndrome of altered cardiovascular, craniofacial, neurocognitive and skeletal development caused by mutations in TGFBR1 or TGFBR2. Nat Genet. 2005;37(3):275-281. https://doi. org/10.1038/ng1511.

4. Van Hemelrijk C, Renard M, Loeys B. The Loeys-Dietz syndrome: an update for the clinician. Curr Opin Cardiol. 2010;25(6):546-551. https://doi.org/10.1097/ HCO.0b013e32833f0220. 
5. Yetman AT, Beroukhim RS, Ivy DD, Manchester D. Importance of the clinical recognition of LoeysDietz syndrome in the neonatal period. Pediatrics. 2007;119(5):e1199-1202. https://doi.org/10.1542/ peds.2006-2886.

6. Muramatsu Y, Kosho T, Magota M, et al. Progressive aortic root and pulmonary artery aneurysms in a neonate with Loeys-Dietz syndrome type 1B. Am J Med Genet A. 2010;152A(2):417-421. https://doi. org/10.1002/ajmg.a.33263.

7. Chung BH, Bradley T, Grosse-Wortmann L, et al. Hand and fibrillin-1 deposition abnormalities in LoeysDietz syndrome - expanding the clinical spectrum. Am J Med Genet A. 2014;164A(2):461-466. https://doi. org/10.1002/ajmg.a.36246.

8. Viassolo V, Lituania M, Marasini M, et al. Fetal aortic root dilation: a prenatal feature of the Loeys-Dietz syndrome. Prenat Diagn. 2006;26(11):1081-1083. https:// doi.org/10.1002/pd.1565.

9. Kawazu Y, Inamura N, Kayatani F, et al. Prenatal complex congenital heart disease with Loeys-Dietz syndrome. Cardiol Young. 2012;22(1):116-119. https://doi. org/10.1017/S1047951111001028.

10. Ozawa H, Kawata H, Iwai S, et al. Pulmonary artery rupture after bilateral pulmonary artery banding in a neonate with Loeys-Dietz syndrome and an interrupted aortic arch complex: report of a case. Surg Today. 2015;45(4):495-497. https://doi.org/10.1007/ s00595-014-0910-8.

11. Woolnough R, Dhawan A, Dow K, Walia JS. Are patients with Loeys-Dietz syndrome misdiagnosed with beals syndrome? Pediatrics. 2017;139(3). https://doi. org/10.1542/peds.2016-1281.

12. Журавлева Л.В., Романенко А.Р. Поражение сердечно-сосудистой системы при наследственных заболеваниях соединительной ткани // Східноєвропейський журнал внутрішньої та сімейної медицини. - 2016. - № 1. - С. 104-110. [Zhuravleva LV, Romanenko AR. Involvement of cardiovascular system in hereditary disorders of connective tissue.

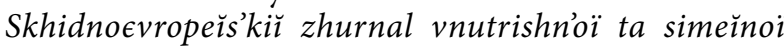
meditsini. 2016;(1):104-110. (In Russ.)]

13. van de Laar IM, Oldenburg RA, Pals G, et al. Mutations in SMAD3 cause a syndromic form of aortic aneurysms and dissections with early-onset osteoarthritis. Nat Genet. 2011;43(2):121-126. https://doi.org/10.1038/ ng.744.

14. Regalado ES, Guo DC, Villamizar C, et al. Exome sequencing identifies SMAD3 mutations as a cause of familial thoracic aortic aneurysm and dissection with intracranial and other arterial aneurysms. Circ Res. 2011;109(6):680-686. https://doi.org/10.1161/ CIRCRESAHA.111.248161.

15. Lindsay ME, Schepers D, Bolar NA, et al. Loss-offunction mutations in TGFB2 cause a syndromic presentation of thoracic aortic aneurysm. Nat Genet. 2012;44(8):922-927. https://doi.org/10.1038/ng.2349.

16. Boileau C, Guo DC, Hanna N, et al. TGFB2 mutations cause familial thoracic aortic aneurysms and dissections associated with mild systemic features of Marfan syndrome. Nat Genet. 2012;44(8):916-921. https://doi. org/10.1038/ng.2348.

17. Bertoli-Avella AM, Gillis E, Morisaki H, et al. Mutations in a TGF-beta ligand, TGFB3, cause syndromic aortic aneurysms and dissections. J Am Coll Cardiol. 2015;65(13):1324-1336. https://doi.org/10.1016/ j.jacc.2015.01.040.

18. Meester JAN, Verstraeten A, Schepers D, et al. Differences in manifestations of Marfan syndrome, EhlersDanlos syndrome, and Loeys-Dietz syndrome. Ann Cardiothorac Surg. 2017;6(6):582-594. https://doi. org/10.21037/acs.2017.11.03.

19. loeysdietz.org [Internet]. Loeys-Dietz Syndrome Foundation [cited 07 feb 2020]. Available from: https:// www.loeysdietz.org/en/medical-information.

20. Malhotra A, Westesson PL. Loeys-Dietz syndrome. Pediatr Radiol. 2009;39(9):1015. https://doi.org/10.1007/ s00247-009-1252-3.

21. Williams JA, Loeys BL, Nwakanma LU, et al. Early surgical experience with Loeys-Dietz: a new syndrome of aggressive thoracic aortic aneurysm disease. Ann Thorac Surg. 2007;83(2):S757-763. https://doi.org/10.1016/ j.athoracsur.2006.10.091.

22. van de Laar IM, van der Linde D, Oei EH, et al. Phenotypic spectrum of the SMAD3-related aneurysmsosteoarthritis syndrome. J Med Genet. 2012;49(1):47-57. https://doi.org/10.1136/jmedgenet-2011-100382.

23. Renard M, Callewaert B, Malfait F, et al. Thoracic aortic-aneurysm and dissection in association with significant mitral valve disease caused by mutations in TGFB2. Int J Cardiol. 2013;165(3):584-587. https://doi. org/10.1016/j.ijcard.2012.09.029.

24. van der Linde D, van de Laar IM, Bertoli-Avella AM, et al. Aggressive cardiovascular phenotype of aneurysms-osteoarthritis syndrome caused by pathogenic SMAD3 variants. J Am Coll Cardiol. 2012;60(5):397-403. https://doi.org/10.1016/j.jacc.2011.12.052.

25. Eckman PM, Hsich E, Rodriguez ER, et al. Impaired systolic function in Loeys-Dietz syndrome: a novel cardiomyopathy? Circ Heart Fail. 2009;2(6):707-708. https:// doi.org/10.1161/CIRCHEARTFAILURE.109.888636.

26. Arslan-Kirchner M, Epplen JT, Faivre L, et al. Clinical utility gene card for: Loeys-Dietz syndrome (TGFBR1/2) and related phenotypes. Eur J Hum Genet. 2011;19(10). https://doi.org/10.1038/ejhg.2011.68.

27. Edelman JJ, Ramponi F, Bannon PG, Jeremy R. Familial aortic aneurysm and dissection due to transforming growth factor-beta receptor 2 mutation. Interact Cardiovasc Thorac Surg. 2011;12(5):863-865. https:// doi.org/10.1510/icvts.2010.258681.

28. Williams JB, McCann RL, Hughes GC. Total aortic replacement in Loeys-Dietz syndrome. J Card Surg. 2011;26(3):304-308. https://doi.org/10.1111/j.15408191.2011.01224.x.

29. Cleuziou J, Eichinger WB, Schreiber C, Lange R. Aortic root replacement with re-implantation technique in an infant with Loeys-Dietz syndrome and a bicuspid aortic valve. Pediatr Cardiol. 2010;31(1):117-119. https:// doi.org/10.1007/s00246-009-9541-z. 
30. Erkula G, Sponseller PD, Paulsen LC, et al. Musculoskeletal findings of Loeys-Dietz syndrome. J Bone Joint Surg Am. 2010;92(9):1876-1883. https://doi. org/10.2106/JBJS.I.01140.

31. Ben Amor IM, Edouard T, Glorieux FH, et al. Low bone mass and high material bone density in two patients with Loeys-Dietz syndrome caused by transforming growth factor beta receptor 2 mutations. J Bone Miner Res. 2012;27(3):713-718. https://doi.org/10.1002/ jbmr.1470.

32. Kirmani S, Tebben PJ, Lteif AN, et al. Germline TGF-beta receptor mutations and skeletal fragility: a report on two patients with Loeys-Dietz syndrome. Am J Med Genet A. 2010;152A(4):1016-1019. https:// doi.org/10.1002/ajmg.a.33356.

33. Frischmeyer-Guerrerio PA, Guerrerio AL, Oswald G, et al. TGFbeta receptor mutations impose a strong predisposition for human allergic disease. Sci Transl Med. 2013;5(195):195ra194. https://doi.org/10.1126/scitranslmed.3006448.

34. Attias D, Mansencal N, Auvert B, et al. Prevalence, characteristics, and outcomes of patients presenting with cardiogenic unilateral pulmonary edema. Circula- tion. 2010;122(11):1109-1115. https://doi.org/10.1161/ CIRCULATIONAHA.109.934950.

35. Verstraeten A, Alaerts M, Van Laer L, Loeys B. Marfan syndrome and related disorders: 25 years of gene discovery. Hum Mutat. 2016;37(6):524-531. https://doi. org/10.1002/humu.22977.

36. Семячкина А.Н., Близнец Е.А., Воинова В.Ю., и др. Синдром Билса (врожденная контрактурная арахнодактилия) у детей: клиническая симптоматика, диагностика, лечение и профилактика // Российский вестник перинатологии и педиатрии. 2016. - T. 61. - № 5. - C. 47-51. [Semyachkina AN, Bliznets EA, Voinova V., et al. Beals syndrome (congenital contractural arachnodactyly) in children: Clinical symptoms, diagnosis, treatment, and prevention. Rossiǔskiu vestnik perinatologii $i$ pediatrii. 2016;61(5):47-51. (In Russ.)]. doi.org/10.21508/10274065-2016-61-5-47-51.

37. Valenzuela I, Fernandez-Alvarez P, Munell F, et al. Arthrogryposis as neonatal presentation of Loeys-Dietz syndrome due to a novel TGFBR2 mutation. Eur J Med Genet. 2017;60(6):303-307. https://doi.org/10.1016/ j.ejmg.2017.03.010.
Ольга Евгеньевна Агранович - д-р мед. наук, руководитель отделения артрогрипоза, ФГБУ «НМИЦ детской травматологии и ортопедии имени Г.И. Турнера» Минздрава России, Санкт-Петербург. https://orcid.org/00000002-6655-4108. E-mail: olga_agranovich@yahoo.com.

Сергей Юрьевич Семенов - врач - травматолог-ортопед, детский хирург, ГБУЗ «Детская городская больница № 22», Санкт-Петербург. https://orcid.org/0000-00027743-2050. E-mail: sergey2810@yandex.ru.
Olga E. Agranovich - MD, PhD, D.Sc., Head of the Department of Arthrogryposis, H. Turner National Medical Research Center for Children's Orthopedics and Trauma Surgery, Saint Petersburg, Russia. https://orcid.org/00000002-6655-4108. E-mail: olga_agranovich@yahoo.com.

Sergey Yu. Semenov - MD, orthopedic and trauma surgeon, pediatric surgeon, State Children's City Hospital No. 22, Saint Petersburg. https://orcid.org/00000002-7743-2050. E-mail: sergey2810@yandex.ru. 
Евгения Федоровна Микиашвили - врач - травматолог-ортопед отделения артрогрипоза, ФГБУ «НМИЦ детской травматологии и ортопедии имени Г.И. Турнера» Минздрава России, Санкт-Петербург. https://orcid. org/0000-0003-1286-3594. E-mail: mikiashviliy@bk.ru.

Светлана Владимировна Саранцева - д-р биол. наук, заведующая лабораторией экспериментальной и прикладной генетики, заместитель директора по научной работе, ФГБУ «Петербургский институт ядерной физики им. Б.П. Константинова» НИЦ «Курчатовский институт», Санкт-Петербург. https://orcid.org/00000002-3943-7504. E-mail: sarantseva_sv@pnpi.nrcki.ru.
Eugeniya F. Mikiashvili - MD, orthopedic and trauma surgeon of the Department of Arthrogryposis, H. Turner National Medical Research Center for Children's Orthopedics and Trauma Surgery, Saint Petersburg, Russia. https://orcid.org/0000-0003-1286-3594. E-mail: mikiashviliy@bk.ru.

Svetlana V. Sarantseva - PhD, D.Sc., Head of Laboratory of Experimental and Applied Genetics, Deputy Director for Science, Petersburg Nuclear Physics Institute named by B.P. Konstantinov of NRC Kurchatov Institute, Leningrad Region, Russia. https://orcid.org/0000-0002-3943-7504. E-mail: sarantseva_sv@pnpi.nrcki.ru. 